Article

\title{
A Simple and Efficient Process for Large Scale Glycerol Oligomerization by Microwave Irradiation
}

\author{
Rémi Nguyen ${ }^{1}$, Nicolas Galy ${ }^{1}$, Abhishek K. Singh ${ }^{2}$, Florian Paulus ${ }^{3}$, Daniel Stöbener ${ }^{3}$, \\ Cathleen Schlesener ${ }^{3}$, Sunil K. Sharma ${ }^{2}$, Rainer Haag ${ }^{3}$ and Christophe Len ${ }^{1, *}$ \\ 1 Sorbonne Universités, Université de Technologie Compiègne, Centre de Recherche Royallieu, CS-60319, \\ F-60203 Compiègne CEDEX, France; nguyen.remi@rocketmail.com (R.N.); ngaly@laposte.net (N.G.) \\ 2 Department of Chemistry, University of Delhi, Delhi-110007, India; abhikmcdu@gmail.com (A.K.S.); \\ sk.sharma90@gmail.com (S.K.S.) \\ 3 Institut für Chemie und Biochemie, Freie Universität Berlin, Takiustraße 3, 14195 Berlin, Germany; \\ florian.paulus@fu-berlin.de (F.P.); daniel.stoebener@wudl.de (D.S.); diecathi@zedat.fu-berlin.de (C.S.); \\ haag@zedat.fu-berlin.de (R.H.) \\ * Correspondence: christophe.len@utc.fr; Tel.: +33-(0)3-44-23-43-23; Fax: +33-(0)3-44-97-15-91 \\ Academic Editor: Keith Hohn \\ Received: 28 February 2017; Accepted: 11 April 2017; Published: 19 April 2017
}

\begin{abstract}
Herein, an optimized method for $100 \mathrm{~g}$ scale synthesis of glycerol oligomers using a microwave multimode source and the low priced $\mathrm{K}_{2} \mathrm{CO}_{3}$ as catalyst is reported. This method allows the complete conversion of glycerol to its oligomers in only $30 \mathrm{~min}$, yielding molecular weights up to $1000 \mathrm{~g} \mathrm{~mol}^{-1}$. Furthermore, a simple iterative purification process, involving the precipitation of the crude product in acetone and methanol, affords a final product composed of larger oligomers with a narrow dispersity $(\mathrm{D}<1.5)$.
\end{abstract}

Keywords: glycerol; oligomerization; microwave; catalysis

\section{Introduction}

The development of biofuel industry produces large quantities of glycerol, making that molecule an important biochemical platform [1,2]. Among the products derived from that renewable resource, glycerol oligomers and their derivatives have proved useful for various applications such as food [3] and cosmetics $[4,5]$. Large hyperbranched polyglycerols have also been prepared for a wide range of applications, e.g., polymer therapeutics and drug delivery [6], but those polymers are not obtained directly from glycerol.

Indeed, direct glycerol polymerization (Scheme 1) is slow, even at high temperatures, and only small weight oligomers are obtained [7,8]. However, the use of microwave heating has been long known to increase the rate of organic reactions [9], even though its exact role in the reaction is a matter of intense discussion [10,11]. It is rather interesting to note that microwaves have been recently applied to the formation of similar glycerol oligomers [12,13]. Preparation of oligomers with an average degree of polymerization $\left(\mathrm{DP}_{\mathrm{n}}\right.$ ) ranging from 13 to 25 has also been claimed. However, a hydroxyl index was the only way to prove the existence of these oligomers with increasing molecular masses. 


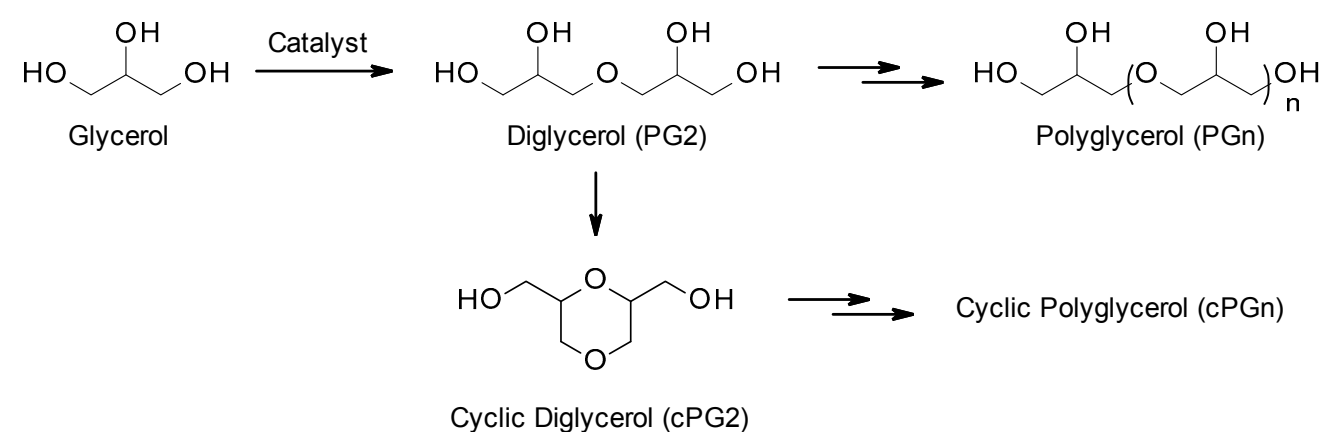

Scheme 1. Glycerol direct polymerization.

Although a variety of catalysts have been reported for glycerol oligomerization, heterogeneous catalysts in particular show good results [14-19], but most of them are quite expensive and can be altered at high temperatures. Homogeneous acid catalysts on the other hand can lead to dehydration reactions with toxic products such as acrolein $[20,21]$. In contrast, basic homogeneous catalysts appear safer and less expensive, and thus several alkaline species have been studied [19,22-25]. Among them, potassium carbonate $\left(\mathrm{K}_{2} \mathrm{CO}_{3}\right)$ has not attracted much focus so far, despite being a very active catalyst [22,23]. Indeed, a preliminary qualitative screening of several alkaline bases showed a quicker conversion of glycerol with $\mathrm{K}_{2} \mathrm{CO}_{3}$ compared to other homogeneous bases such as $\mathrm{NaOH}, \mathrm{KOH}$, and so on.

The approach for our work was to test various processes and conditions for direct oligomerization of glycerol, using microwave heating with $\mathrm{K}_{2} \mathrm{CO}_{3}$ as a catalyst, in order to ensure a quick conversion of glycerol and the formation of the largest oligomers possible. We chose to focus primarily on the engineering challenges of the reaction and to leave detailed catalyst optimization for further studies. Additionally, we report herein a simple purification method to refine the final product by eliminating small oligomers.

\section{Results and Discussion}

\subsection{Preliminary Test with Monomode Reactor}

Given the various microwave equipment commercially available, preliminary studies were performed using a monomode SAIREM reactor, allowing a fine control of the temperature and the delivered power. Moreover, this system was used with an open graduated flask, favoring the evaporation of water formed during the reaction and thus displacing the equilibrium toward the olymerization reaction.

The oligomerization of glycerol was attempted using $\mathrm{K}_{2} \mathrm{CO}_{3}$ as a catalyst, which has been reported in the literature to be an active basic catalyst for glycerol oligomerization [22]. The reaction temperature was set to $237^{\circ} \mathrm{C}$, close to the upper tolerance limit of the microwave system. A nearly constant reaction temperature was maintained by an automated power regulation.

After $16 \mathrm{~h}$, the glycerol was almost entirely converted (95\%), and the formation of three oligoglycerol species, with a multimodal overall weight average molecular weight $\mathrm{M}_{\mathrm{w}}=704 \mathrm{Da}$ and a dispersity (D) of 2.1, was observed (Figure 1). The oligomers in this molecular weight range consist of 4-9 repeating units (r.u.). A comparable distribution was determined by mass spectrometry analysis (Figure S1). Although GPC analysis was able to separate three oligomer species more clearly, mass analysis showed that there are both linear and cyclic structures present in the mixture. The cyclic oligomers $\left(\left[\mathrm{M}_{\mathrm{cyc}}+\mathrm{K}\right]^{+}: \mathrm{m} / \mathrm{z}=483.18,557.22,631.26\right)$ is mainly consisting of regular linear repeating units, including one additional cyclized r.u. with an unspecified position in the oligomer chain. However, the linear oligomers $\left([\mathrm{M}+\mathrm{K}]^{+}: \mathrm{m} / \mathrm{z}=501.19,575.23,649.27\right)$ exhibit a higher relative abundance. Interestingly, significant presence of smaller oligomers with two cyclized r.u. 
$\left(\left[\mathrm{M}_{\mathrm{bicyc}}+\mathrm{K}\right]^{+}: \mathrm{m} / \mathrm{z}=393.17,467.81,541.24\right)$, and even three cyclized r.u. $\left(\left[\mathrm{M}_{\text {tricyc }}+\mathrm{K}\right]^{+}:\right.$449.20, 523.23, 597.27) are detected.

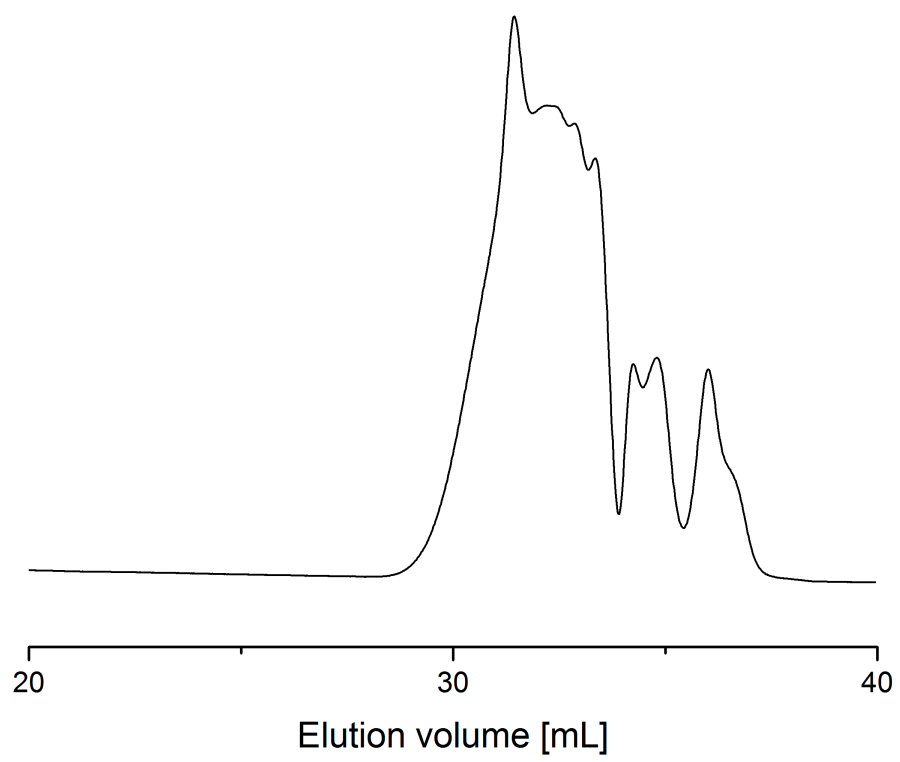

Figure 1. Gel permeation chromatography (GPC) eluogram of glycerol oligomers obtained using SAIREM MW open reactor with $\mathrm{K}_{2} \mathrm{CO}_{3}\left(4 \mathrm{wt} \%\right.$ ) as catalyst, $237^{\circ} \mathrm{C}, 16 \mathrm{~h}$.

The classical thermal oligomerization described in the literature did not yield any significant molecular weight increase nor any effect on glycerol conversion, an observation that supports the recent literature on the subject [11]. In consequence, the reaction is expected to proceed faster at higher temperatures, requiring a higher microwave power. Therefore, we designed a new batch system around a multimode microwave source.

\subsection{Process with Multimode Reactor}

We choose a multimode Samsung MW71X apparatus (Figures S2 and S3), which allows the use of up to $800 \mathrm{~W}$ microwave power and possess a larger reactor size. As the temperature in this system cannot be controlled, we relied on the commercial power of the apparatus for tuning. Reactions performed with 300, 600, and $800 \mathrm{~W}$ at an $80 \mathrm{~g}$ scale displayed similar patterns, with large oligomers being formed in a relatively short time (Figure 2), depending on the power input. More precisely, the analysis by gel permeation chromatography showed a multimodal distribution, with a first species corresponding to small linear and cyclic oligomers (as observed by gas chromatography) and a second species of larger oligomers. By this method, and in comparison with the limited monomode process, comparable oligomers and polymers were obtained in short periods of time. Given the possible glycerol oligomers obtained during oligomerization of glycerol (PG1), different linear and cyclic oligomers can be produced statistically as different mixtures: dimers (PG2), cyclic dimers (cPG2), trimers (PG3), cyclic trimers (cPG3), tetramers (PG4), pentamers (PG5), hexamers (PG6), and so on. Concerning the lower polyglycerol, the possible linear dimers (PG2) observed by GC analysis after silylation by $N, O$-bis(trimethylsilyl)acetamide [26] are as follows: $\alpha, \alpha$-diglycerol, $\alpha, \beta$-diglycerol, and $\beta, \beta$-diglycerol; the linear trimers (PG3) are as follows: $\alpha, \alpha-\alpha, \alpha$-triglycerol, $\alpha, \alpha-\beta, \alpha$-triglycerol, $\alpha, \alpha-\alpha, \beta$-triglycerol, $\alpha, \beta$ - $\alpha, \beta$-triglycerol, $\beta, \alpha-\alpha, \beta$-triglycerol, $\alpha, \alpha-\beta, \beta$-triglycerol, and $\beta, \alpha-\beta, \beta$-triglycerol. The cyclic dimers (cPG2) are as follows: cyclic $\alpha, \beta-\alpha, \beta$-diglycerol, cyclic $\alpha, \alpha-\beta, \beta$-diglycerol, cyclic $\alpha, \alpha-\alpha, \alpha$-diglycerol, cyclic $\alpha, \alpha-\alpha, \beta$-diglycerol, and bicyclic $\alpha, \alpha-\alpha, \alpha-\beta, \beta$-diglycerol (Figure 3). For larger oligomers, mixtures of linear, branched and cyclic molecules are obtained, and it is difficult to perform a detailed structural analysis. Despite the multimodal distribution, a particular oligo-formation with 11 r.u. was observed in all reactions by GPC (Figure 3). 

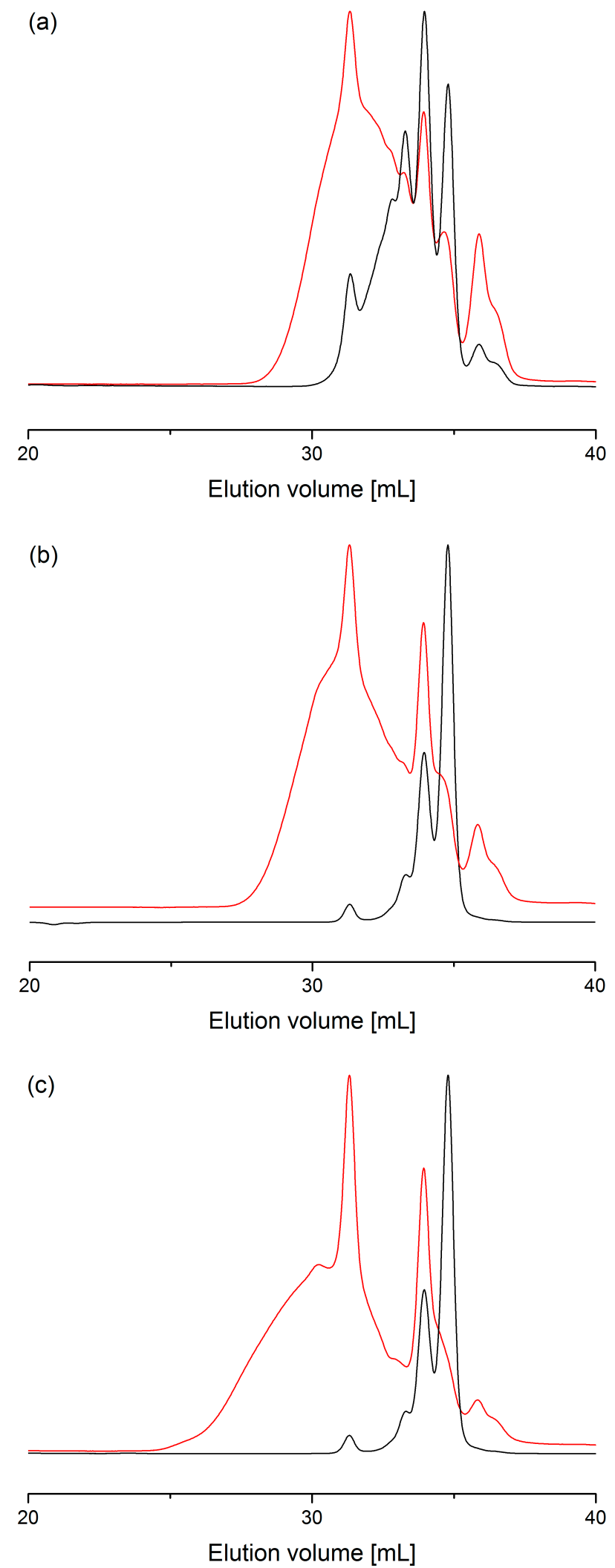

Figure 2. GPC eluogram of glycerol oligomers obtained with $\mathrm{K}_{2} \mathrm{CO}_{3}(4 \mathrm{wt} \%$ ) as catalyst: (a) $300 \mathrm{~W}$ after 20 (black) and $30 \mathrm{~min}$ (red); (b) $600 \mathrm{~W}$ after 5 (black) and $10 \mathrm{~min} 30 \mathrm{~s}$ (red); (c) $800 \mathrm{~W}$ after 4 (black) and $6 \mathrm{~min} 20 \mathrm{~s}$ (red). 
PG2<smiles>OCC(O)COCC(O)CO</smiles>

$\alpha, \alpha$-diglycerol<smiles>OCC(O)COC(CO)CO</smiles>

$\alpha, \beta$-diglycerol<smiles>OCC(CO)OC(CO)CO</smiles>

$\beta, \beta$-diglycerol

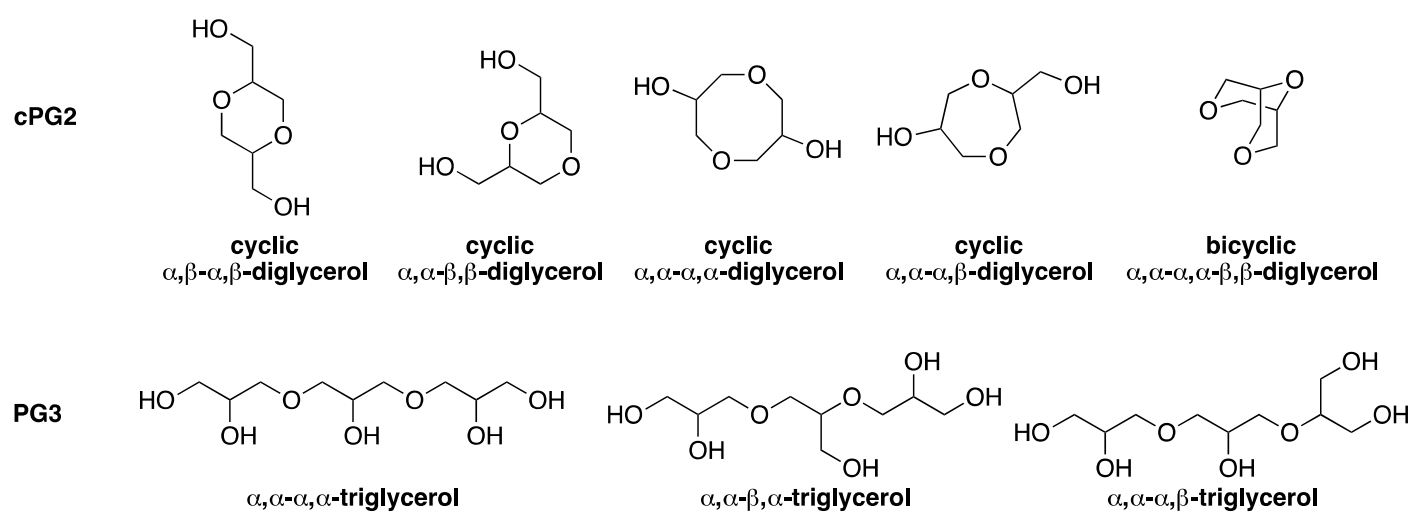<smiles>OCC(O)COC(CO)COC(CO)CO</smiles>

$\alpha, \beta-\alpha, \beta$-triglycerol

$\beta, \alpha-\alpha, \beta$-triglycerol

$\alpha, \alpha-\beta, \beta$-triglycerol

$\beta, \alpha-\beta, \beta$-triglycerol

Figure 3. Linear/branched isomers of diglycerol (PG2) and triglycerol (PG3) and cyclic isomers of diglycerol (cPG2).

The final oligomer mixtures were additionally analyzed by mass spectrometry (Figure S4, $300 \mathrm{~W}$; Figure S5, 600 W; Figure S6, 800 W). Comparable to the structural distribution obtained in the monomode reactor, the oligomers are separated in a regular linear oligomers, a structure exhibiting a cyclic r.u., and another with two cyclic r.u. Interestingly, the relative abundance of the monocyclic species $\left(\left[\mathrm{M}_{\mathrm{cyc}}+\mathrm{K}\right]^{+}: \mathrm{m} / \mathrm{z}=631.26,705.29,779.34\right)$ was more prominent at lower energy inputs of $300 \mathrm{~W}$ and $600 \mathrm{~W}$, whereas the reaction at $800 \mathrm{~W}$ yielded an increased relative amount of the bicyclic species $\left(\left[\mathrm{M}_{\mathrm{bicyc}}+\mathrm{K}\right]^{+}: \mathrm{m} / \mathrm{z}=539.21,613.25,687.28\right)$. The relative abundance of the linear oligomers $\left([\mathrm{M}+\mathrm{K}]^{+}: \mathrm{m} / \mathrm{z}=649.27,723.30,797.34\right)$ also decreases with the increase in delivered power.

As observed for the oligomerization in the monomode reactor, a tricyclic species $\left(\left[\mathrm{M}_{\text {tricyc }}+\mathrm{K}\right]^{+}\right.$: $669.3,743.3,817.3$ ) was detected for all power inputs, whereas the relative abundance is smaller for the lowest delivered power of $300 \mathrm{~W}$.

Evaporation also played an important role, especially at higher power. For reaction at $600 \mathrm{~W}$ and $800 \mathrm{~W}$, the cooling system trapped significant amount of material. Further analysis by GC analysis showed that, in addition to water, glycerol was the main component of the vapor phase. This evaporated glycerol represented a crucial loss of materials. Indeed, a maximum $38 \%$ of the starting reagent was lost at $800 \mathrm{~W}$ (Table 1). Furthermore, small fractions of organic compounds were also evaporated from the reactor. These compounds were identified with GC analysis as cyclic diglycerols. 
Table 1. Oligomerization reaction with $\mathrm{K}_{2} \mathrm{CO}_{3}(4 \mathrm{wt} \%)$ as catalyst, with $76.8 \mathrm{~g}$ of initial glycerol (Figure 3, red eluograms).

\begin{tabular}{cccccccc}
\hline Entry & Power (W) & Time [min] & $\mathbf{M}_{\mathbf{W}}{ }^{\mathbf{a}}$ & $\mathbf{M}_{\mathbf{N}}{ }^{\mathbf{b}}$ & $\mathbf{D}^{\mathbf{c}}$ & Evaporated Glycerol [Units] $^{\text {Ratio }^{\mathbf{d}}}$ [\%] \\
\hline 1 & 300 & 30 & 887 & 358 & 2.5 & 2.8 & 3.6 \\
2 & 600 & 10.5 & 1244 & 406 & 3.1 & 20.3 & 26.4 \\
3 & 800 & 6.33 & 2833 & 479 & 5.9 & 29.1 & 37.9 \\
\hline
\end{tabular}

${ }^{a}$ Weight average molecular weight $\mathrm{M}_{\mathrm{W}}$ are average values obtained from global integration $\mathrm{f}$ GPC eluograms;

${ }^{b}$ Number average molecular weight $\mathrm{M}_{\mathrm{N}}$ are average values obtained from global integration of GPC eluograms;

${ }^{\mathrm{c}}$ Dispersity D are average values obtained from global integration of GPC eluograms; ${ }^{\mathrm{d}}$ Ratio of evaporated glycerol over starting glycerol.

Another problem caused by excessive heat was demonstrated when starting the reaction with $\alpha, \alpha^{\prime}$-diglycerol as the main reagent. Indeed, if diglycerol was converted into cyclic dimer and larger oligomers, a significant amount of odd number oligomers was formed in the process (Table 2). This last fact suggested that the reaction is equilibrated, making a cleavage of diglycerol into glycerol possible under those conditions (Figures S7-S12).

Table 2. Gas chromatography (GC) results for the reaction with diglycerol mixture ( $96 \mathrm{wt} \%$ ) as reagent, and $\mathrm{K}_{2} \mathrm{CO}_{3}(4 \mathrm{wt} \%)$ as catalyst, at $300 \mathrm{~W}$.

\begin{tabular}{|c|c|c|c|c|c|c|c|c|c|c|}
\hline Entry & Time (min) & $\mathrm{PG1}^{\mathrm{a}}[\%]$ & cPG2 $^{\mathrm{b}}[\%]$ & PG2 [\%] & $\mathrm{cPG}^{\mathrm{c}}[\%]$ & PG3 [\%] & PG4 [\%] & PG5 [\%] & PG6 [\%] & PG7 [\%] \\
\hline 1 & 0 & 3.3 & 7.8 & 81.9 & 0.0 & 0.4 & 6.0 & 0.0 & 0.3 & 0.0 \\
\hline 2 & 5 & 3.1 & 7.8 & 81.6 & 0.0 & 0.4 & 6.2 & 0.0 & 0.4 & 0.0 \\
\hline 3 & 10 & 3.3 & 7.7 & 81.2 & 0.0 & 0.6 & 6.3 & 0.0 & 0.4 & 0.0 \\
\hline 4 & 15 & 6.3 & 10.6 & 52.4 & 1.1 & 8.2 & 12.7 & 3.1 & 3.1 & 0.9 \\
\hline 5 & 20 & 4.9 & 20.0 & 21.9 & 4.2 & 9.0 & 12.6 & 8.5 & 8.3 & 5.3 \\
\hline
\end{tabular}

In order to optimize the process, we decided to address the issues of reagent evaporation and oligomer dispersity by controlling the heating power in a more subtle way, and by redesigning the reactor.

\subsection{Process Optimization}

To avoid glycerol evaporation, we simply used a distillation column instead of an air refrigerant. Furthermore, this setup allows the presence of a thermometer on top of the column to ensure that the vapor phase is mainly composed of water. Thus, we adjusted the microwave power in order to keep the head temperature around $110^{\circ} \mathrm{C}$, assuming the temperature in the reacting solution to be around $290{ }^{\circ} \mathrm{C}$ (glycerol reflux) (Figures S13 and S14). Using an amount of glycerol and $\mathrm{K}_{2} \mathrm{CO}_{3}$ mixture increased from $80 \mathrm{~g}$ to $100 \mathrm{~g}$, we finally selected a sequence of $4 \mathrm{~min}$ at $800 \mathrm{~W}$, followed by another $13 \mathrm{~min}$ at $300 \mathrm{~W}$.

Using this method, only $2.1 \%$ of the starting glycerol was evaporated once the reaction was completed. However, even after controlling the reagent evaporation, GPC measurement still showed a rather low molecular weight with $\mathrm{M}_{\mathrm{w}}=725 \mathrm{Da}$ and a poor dispersity of 2.3 , as observed earlier, because of the formation of low molecular weight cyclic products (Figure 4). In order to check the reproducibility, the reaction was repeated three times and analyzed by GPC (Figure S15a-c). The GPC profiles are quite identical suggesting a good reproductibility. 


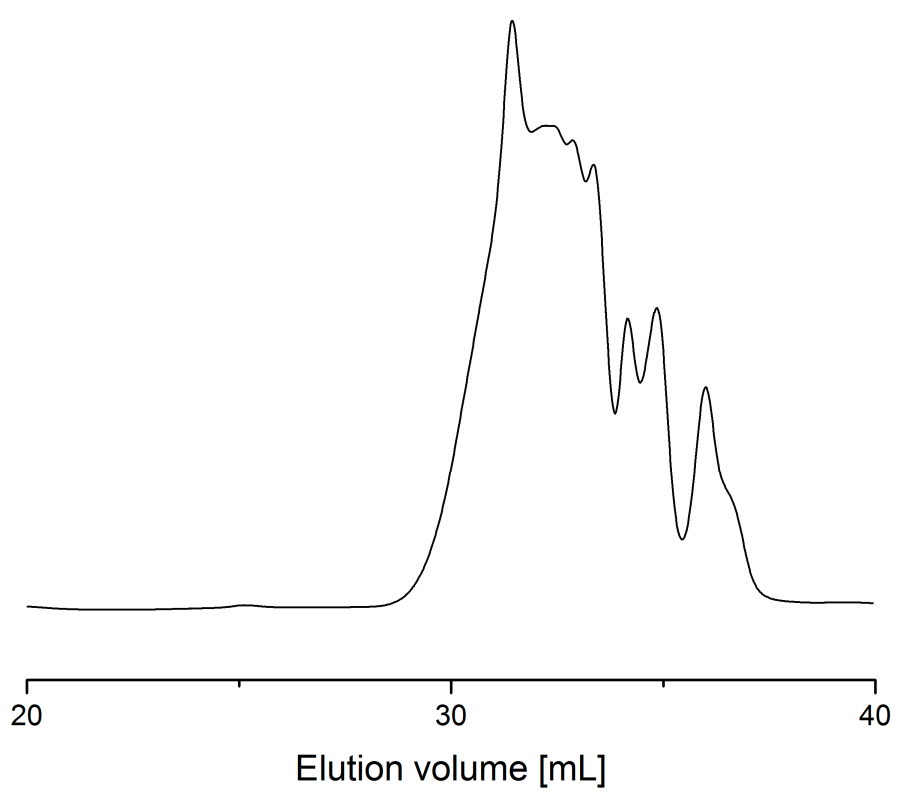

Figure 4. GPC eluogram of glycerol oligomers obtained with $\mathrm{K}_{2} \mathrm{CO}_{3}(4 \mathrm{wt} \%)$ as a catalyst with the microwave optimized process.

In order to improve the polydispersity by separating the low molecular weight byproducts, we also devised a simple purification process. The newly prepared, crude product was first dissolved in a minimal amount of methanol, and then precipitated with the addition in cold acetone (Figure 6). Consequently, the resulting precipitate was enriched with large oligomers, while smaller product remained in the solution phase. An iteration of this purification process yielded good results after three precipitation steps in the first cycle. Further, two more cycles with a decreasing number of precipitation steps yielded a highly pure oligomer mixture compared to the crude product (Figure 5). Indeed, starting with $10 \mathrm{~g}$ of crude product, we obtained $2.6 \mathrm{~g}$ of a glycerol oligomer mixture with a high molecular weight of $\mathrm{M}_{\mathrm{W}}=1302 \mathrm{Da}$ and a low dispersity of 1.5 .

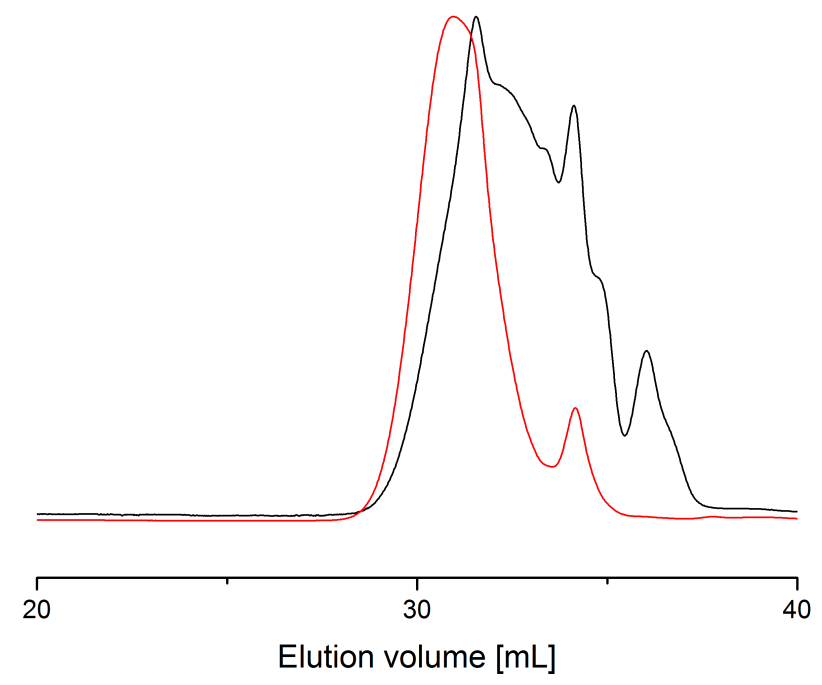

Figure 5. Comparison of the crude (black) product and the purified oligoglycerol mixture after three precipitation cycles (red).

All precipitates and the remaining supernatant were subjected to GPC (Figures S16-S18) and ESI analysis (Figures S19-S28). Interestingly, the precipitates also consisted of a smaller molecular weight 
fraction. This smaller molecular weight fraction was significantly reduced in Cycles 2 and 3 with molecular weight distribution of the separated oligomers becoming more similar to the precipitate. Therefore, a further precipitation cycle is rather expected to reduce the amount of oligomers than increase the product purity.

The results from mass spectrometry indicate a similar relative abundance of both the linear $\left([\mathrm{M}+\mathrm{K}]^{+}: \mathrm{m} / \mathrm{z}=575.23,649.27,723.30\right)$ and cyclic $\left(\left[\mathrm{M}_{\mathrm{cyc}}+\mathrm{K}\right]^{+}: \mathrm{m} / \mathrm{z}=631.26,705.29,779.34\right)$ structures in the crude product (Figure S19). Bicyclic $\left(\left[\mathrm{M}_{\mathrm{bicyc}}+\mathrm{K}\right]^{+}: \mathrm{m} / \mathrm{z}=615.28\right)$ and tricyclic $\left(\left[\mathrm{M}_{\text {tricyc }}+\mathrm{K}\right]^{+}: \mathrm{m} / \mathrm{z}=597.27\right)$ oligomers were also detected with a decreasing relative amount. After the first purification cycle, the relative abundance of the linear oligomers in the precipitate increased, whereas the cyclic and lower molecular weight oligomers enriched in the supernatant (Figure S23). Despite a further increase of the linear oligomers in the second purification cycle, this increase was also observed for the supernatant (Figure S26). The relative abundance of the linear oligomers in the final precipitate (Figure S27) was further maximized with an increase of both linear and cyclic oligomers in the remaining supernatant. Finally, the obtained oligomers are shown to be increasingly viscous (Figure S29).

Although this iterative purification method involves the removal of a large part of the material, it yielded a decent amount of polyglycerol from direct glycerol oligomerization, a result never attained in previous studies.

\section{Experimental Section}

Materials and Methods: Glycerol (99\% purity) was purchased from Fisher Scientific (Illkirch, France). Sodium hydroxide $(\mathrm{NaOH})$ and potassium carbonate $\left(\mathrm{K}_{2} \mathrm{CO}_{3}\right)$, and bis (trimethylsilyl) acetamide (BSA) were purchased from Acros Organics (Illkirch, France). The synthesis of linear diglycerol is described in the supporting information.

For analytical mater, linear triglycerol and tetraglycerol were prepared from commercial reagents according to procedures previously described in the literature $[27,28]$.

Preparation of Glycerol and $\mathrm{K}_{2} \mathrm{CO}_{3}$ Mixture: In a $250 \mathrm{~mL}$ beaker, $4 \mathrm{~g}$ of $\mathrm{K}_{2} \mathrm{CO}_{3}$ was added to $96 \mathrm{~g}$ of glycerol. The suspension was magnetically stirred and heated to $80{ }^{\circ} \mathrm{C}$ until complete dissolution of the base.

\subsection{Oligomerization Process}

\subsubsection{Low Power Monomode Reaction (100-200 W)}

An open graduated flask, loaded with $80 \mathrm{~g}$ of the glycerol and $\mathrm{K}_{2} \mathrm{CO}_{3}$ mixture, was placed in a SAIREM Miniflow 200SS monomode microwave apparatus (Sairem, Miribel, France) (Figure S30). The mixture was then stirred at $237^{\circ} \mathrm{C}$, while the temperature was controlled with a probe inside the reaction mixture. The reaction progress was monitored by gas chromatography until the glycerol disappears.

\subsubsection{High Power Multimode Reaction}

A round bottom flask, loaded with $80 \mathrm{~g}$ of the glycerol and $\mathrm{K}_{2} \mathrm{CO}_{3}$ mixture, was placed in a Samsung MW71X multimode microwave oven (Samsung, Malaysia), and connected with a glass tube (air refrigerant) to a condenser where the evaporated material is trapped (Figures S2 and S3).

\subsubsection{Optimized High Power Multimode Process}

A round bottom flask, loaded with $100 \mathrm{~g}$ of the glycerol and $\mathrm{K}_{2} \mathrm{CO}_{3}$ mixture was placed in a Samsung MW71X multimode microwave oven, and connected with a distillation column and a condenser where the evaporated materials were trapped. A T-linkage (glass) allows the head temperature to be measured and controlled (Figures S13 and S14). 


\subsubsection{Purification}

The purification of the crude oligomer mixture was conducted accordingly, if not described differently: $10 \mathrm{~g}$ of the crude product was dissolved in $20 \mathrm{~mL}$ of methanol and added to the $40 \mathrm{~mL}$ of cold acetone in an ice bath. The mixture was allowed to settle for $20 \mathrm{~min}$. Subsequently, the liquid phase was decanted, and obtained precipitate was re-dissolved in methanol. Two more fractions were then subjected to precipitation. The precipitates obtained in all 3 fractions were mixed and subjected to two more cycles of precipitation, which resulted in $2.6 \mathrm{~g}$ of final precipitate, which had a higher amount of glycerol oligomers (Figure 6).

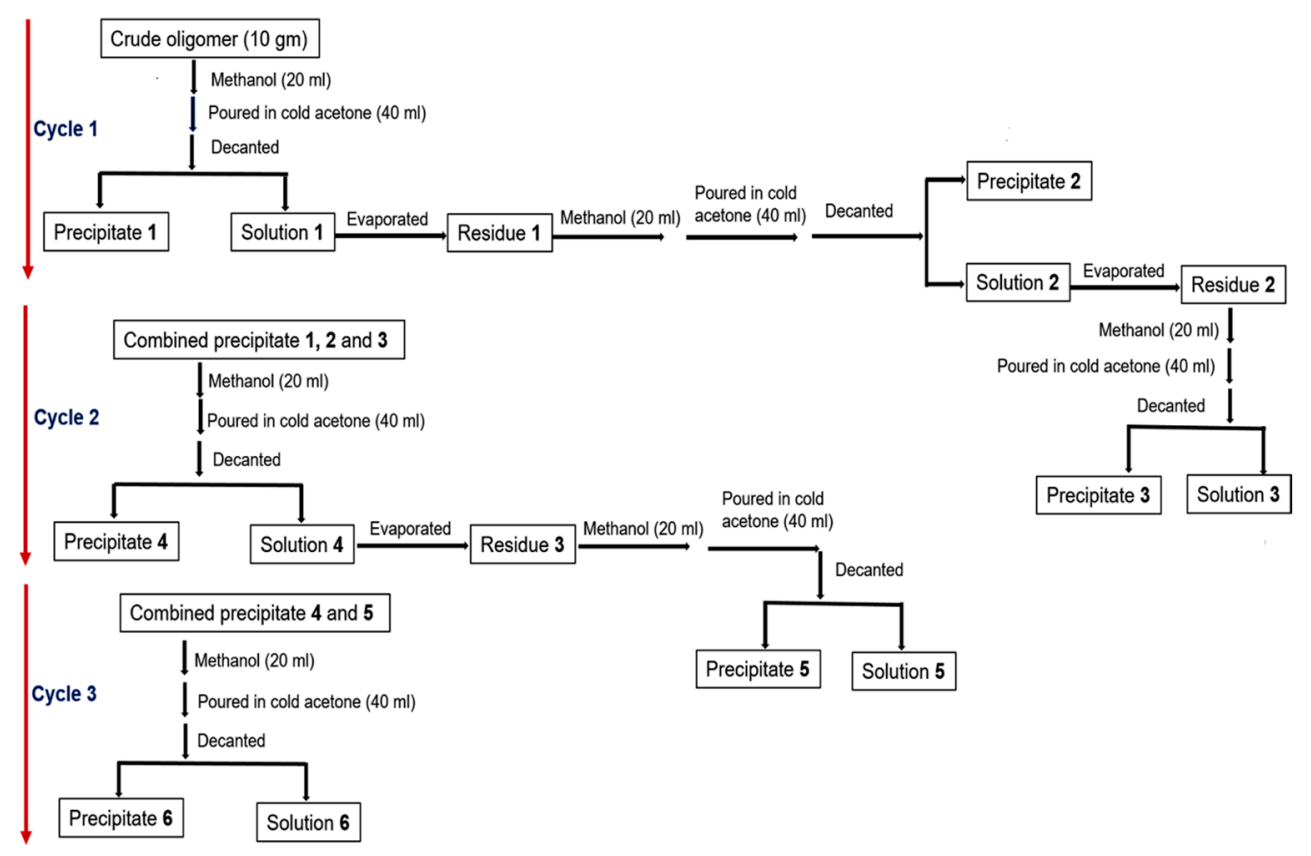

Figure 6. Iterative purification protocol for the separation of smaller oligomers from the product mixture.

\subsection{Analysis}

\subsubsection{Gas Chromatography (GC)}

Gas chromatography analyses were performed on a Perkin-Elmer gas chromatography instrument (Autosystem XL GC) (Perkin-Elmer, Singapore) using an Altech AT HT column with a detector at $300^{\circ} \mathrm{C}$, an injector at $340^{\circ} \mathrm{C}$, and a constant flow of nitrogen of $1 \mathrm{~mL} \mathrm{~min}{ }^{-1}$. The column is heated at $150{ }^{\circ} \mathrm{C}$ for $2 \mathrm{~min}$, and then warmed to $350{ }^{\circ} \mathrm{C}$ with a temperature gradient of $15^{\circ} \mathrm{C} \mathrm{min}-1$ before being held at that temperature for $4.67 \mathrm{~min}$.

Each sample is derivatized before injection according to the following protocol: $0.5 \mathrm{~mL}$ of $\mathrm{N}, \mathrm{O}$-bis(trimethylsilyl)acetamide was added to a $40 \mathrm{mg}$ sample, and the mixture was heated at $50{ }^{\circ} \mathrm{C}$ for $30 \mathrm{~min}$. The solution was then diluted with $1 \mathrm{~mL}$ of ethyl acetate, and $1 \mu \mathrm{L}$ was injected in the gas chromatography column.

Glycerol, linear diglycerol, triglceriol, and tetraglycerol were used as standard samples. The identification of other products is based on previous work by De Meulenaer and coworkers [26].

\subsubsection{Gel Permeation Chromatography (GPC)}

Molecular weight distributions were determined with a size exclusion chromatography (SEC) instrument, equipped with a refractive index detector (operated at $50{ }^{\circ} \mathrm{C}$ ) providing the following parameters: average molecular weight, $M_{n}$, peak molecular weight, $M_{p}$, weight average molecular 
weight, $\mathrm{M}_{\mathrm{w}}$, and dispersity index, $\mathrm{D}$. Measurements were performed under diluted conditions (10 mg mL $\mathrm{mL}^{-1}$, injected volume $20 \mu \mathrm{L}$ ) using an Agilent 1100 solvent delivery system with an ISO pump, a manual injector, and an Agilent 1100 differential refractometer. Three $30 \mathrm{~cm}$ columns in a row (PSS SUPREMA, $5 \mu \mathrm{m}$ particle size) were used at room temperature at a flow rate of $1.0 \mathrm{~mL} \mathrm{~min}-1$ using an aqueous $0.1 \mathrm{M} \mathrm{NaNO}_{3}$ solution as mobile phase. DIN certified Pullulan provided by PSS was used as polymeric standard. Samples with $\mathrm{M}_{n}=342,1080,5500,9200,20 \mathrm{k}, 100 \mathrm{k}, 188.5 \mathrm{k}, 358 \mathrm{k}$, and $636 \mathrm{k}$ and with PDI $=1.00-1.30$ were used for regression. WinGPC Unity from PSS was used for data acquirement and interpretation.

\subsubsection{Mass Spectrometry}

Mass spectrometry was conducted on an Agilent 6210 ESI-TOF (Agilent Technologies, Santa Clara, CA, USA) with a flow rate of $4 \mu \mathrm{L} \mathrm{min}^{-1}$ and a spray voltage of $4 \mathrm{kV}$. The desolvation gas was set to $15 \mathrm{psi}(1 \mathrm{bar})$. Additional method parameters were set to gather the maximum abundance of $[\mathrm{M}+\mathrm{H}]^{+}$ ionized molecules.

\section{Conclusions}

After achieving a partial success in the oligomerization of glycerol by using a commercial monomode microwave reactor, we designed a new system based on a multimode apparatus to obtain the formation of large oligomers directly from glycerol with $\mathrm{K}_{2} \mathrm{CO}_{3}$ as catalyst. It allows quick reactions with the formation of larger polyglycerols than normally observed with direct glycerol oligomerization under thermic activation.

However, this process also affords small cyclic oligomers as byproducts and causes the undesired evaporation of significant amounts of reagent. Excessive heating is also responsible for breaking large oligomers, a fact highlighted when linear diglycerol is substituted with glycerol as the starting reagent.

To solve those issues, the reactor was modified by adding a distillation column, and by modeling the delivered power in order to limit the head temperature to around $110^{\circ} \mathrm{C}$. With this new design, we carried out the reaction on a $100 \mathrm{~g}$ scale with similar results. However, we still observed the evaporation of small amounts of the product.

Using a simple purification process, with the iterative precipitation of the crude product in a mixture of acetone and methanol, we obtained polyglycerols with molecular weights of around $1000 \mathrm{~g} \mathrm{~mol}^{-1}$ and a dispersity of only 1.5 and mainly separated the cyclic oligomers. To the best of our knowledge, it is the first synthesis of such high weight oligo-glycerol, directly from glycerol, in an unequivocal manner.

Supplementary Materials: The following are available online at www.mdpi.com/2073-4344/7/4/123/s1.

Acknowledgments: S.K.S. is thankful to SERB-DST for financial support.

Author Contributions: For research articles with several authors, a short paragraph specifying their individual contributions must be provided. The following statements should be used S.K.S., R.H. and C.L. conceived and designed the experiments; R.N., N.G., A.K.S., D.S. and C.S. performed the experiments; R.N., N.G., A.K.S., F.P., S.K.S., R.H. and C.L. analyzed the data; R.H. and C.L. contributed reagents/materials/analysis tools; S.K.S., R.H. and C.L. wrote the paper." Authorship must be limited to those who have contributed substantially to the work reported.

Conflicts of Interest: The authors declare no competing financial interest.

\section{References}

1. Pagliaro, M.; Ciriminna, R.; Kimura, H.; Rossi, M.; Della Pina, C. From glycerol to value-added products. Angew. Chem. Int. Ed. 2007, 46, 4434-4440. [CrossRef] [PubMed]

2. Zhou, C.-H.; Beltramini, J.N.; Fan, Y.-X.; Lu, G.Q. Chemoselective catalytic conversion of glycerol as a biorenewable source to valuable commodity chemicals. Chem. Soc. Rev. 2008, 37, 527-549. [CrossRef] [PubMed] 
3. Ogawa, A. (Mitsubishi Chemical Corporation). Milk Beverage Containing Sucrose Fatty Acid Ester and Polyglycerol Fatty Acid Ester. World Patent 2004049813, 2004.

4. Perrault, V. (L'Oréal). Cosmetic Composition, Useful in e.g. Spray Bottle, Roll on and Tubing, for Perfuming on Skin, Clothing and an Object, Comprises Aqueous Phase, Volatile Alcohol, Perfume, Non-Volatile Hydrocarbon Oil, and Polyglycerol Ester of Fatty Acid. Fr. Patent 2998783, 2014.

5. Giuliani, G.; Benedusi, A.; Mascolo, A.; Marzani, B.; Bregaglio, G. (Giuliani S.P.A.). Polyglycerol-Azelaic Acid Polyesters for Cosmetic Applications. U.S. Patent 20150196480, 2015.

6. Wilms, D.; Stiriba, S.-E.; Frey, H. Hyperbranched polyglycerols: From the controlled synthesis of biocompatible polyether polyols to multipurpose applications. Acc. Chem. Res. 2010, 43, 129-141. [CrossRef] [PubMed]

7. Martin, A.; Richter, M. Oligomerization of glycerol-A critical review. Eur. J. Lipid Sci. Technol. 2011, 113, 100-117. [CrossRef]

8. Sivaiah, M.V.; Robles-Manuel, S.; Valange, S.; Barrault, J. Recent developments in acid and base-catalyzed etherification of glycerol to polyglycerols. Catal. Today 2012, 198, 305-313. [CrossRef]

9. Mingos, D.M.P.; Baghurst, D.R. Applications of microwave dielectric heating effects to synthetic problems in chemistry. Chem. Soc. Rev. 1991, 20,1-47. [CrossRef]

10. Perreux, L.; Loupy, A. A tentative rationalization of microwave effects in organic synthesis according to the reaction medium, and mechanistic considerations. Tetrahedron 2001, 57, 9199-9223. [CrossRef]

11. Obermayer, D.; Gutmann, B.; Kappe, C.O. Microwave chemistry in silicon carbide reaction vials: Separating thermal from nonthermal effects. Angew. Chem. Int. Ed. 2009, 48, 8321-8324. [CrossRef] [PubMed]

12. Mat Din, N.S.M.N.; Idris, Z.; Kian, Y.S.; Hassan, H.A. Preparation of polyglycerol from palm-biodiesel crude glycerin. J. Oil Palm Res. 2013, 25, 289-297.

13. Bookong, P.; Ruchirawat, S.; Boonyarattanakalin, S. Optimization of microwave-assisted etherification of glycerol to polyglycerols by sodium carbonate as catalyst. Chem. Eng. J. 2015, 275, 253-261. [CrossRef]

14. Clacens, J.-M.; Pouilloux, Y.; Barrault, J. Selective etherification of glycerol to polyglycerols over impregnated basic MCM-41 type mesoporous catalysts. Appl. Catal. A Gen. 2002, 227, 181-190. [CrossRef]

15. Barrault, J.; Clacens, J.-M.; Pouilloux, Y. Selective oligomerization of glycerol over mesoporous catalysts. Top. Catal. 2004, 27, 137-142. [CrossRef]

16. Ruppert, A.M.; Meeldijk, J.D.; Kuipers, B.W.M.; Erné, B.H.; Weckhuysen, B.M. Glycerol etherification over highly active $\mathrm{CaO}$-based materials: New mechanistic aspects and related colloidal particle formation. Chem. Eur. J. 2008, 14, 2016-2024. [CrossRef] [PubMed]

17. Krisnandi, Y.K.; Eckelt, R.; Schneider, M.; Martin, A.; Richter, M. Glycerol upgrading over zeolithes by batch-reactor liquid-phase oligomerization: Heterogeneous versus homogeneous reaction. ChemSusChem 2008, 1, 835-844. [CrossRef] [PubMed]

18. Richter, M.; Eckelt, R.; Krisnandi, Y.K.; Martin, A. Verfahren zur selektiven herstellung von linearem diglycerin. Chem. Ing. Tech. 2008, 80, 1573-1577. [CrossRef]

19. Anuar, M.R.; Abdullah, A.Z.; Othman, M.R. Etherification of glycerol to polyglycerols over hydrotalcite catalyst prepared using a combustion method. Catal. Commun. 2013, 32, 67-70. [CrossRef]

20. Katryniok, B.; Paul, S.; Capron, M.; Dumeignil, F. Towards the sustainable production of acrolein by glycerol dehydration. ChemSusChem 2009, 2, 719-730. [CrossRef] [PubMed]

21. Katryniok, B.; Paul, S.; Bellière-Baca, V.; Rey, P.; Dumeignil, F. Glycerol dehydration to acrolein in the context of new uses of glycerol. Green Chem. 2010, 12, 2079-2098. [CrossRef]

22. Garti, N.; Aserin, A.; Zaidman, B. Polyglycerol esters: Optimization and techno-economic evaluation. J. Am. Oil Chem. Soc. 1981, 58, 878-883. [CrossRef]

23. Cottin, K.; Clacens, J.-M.; Pouilloux, Y.; Barrault, J. Preparation of diglycerol and triglycerol by the direct polymerization of glycerol in the presence of the new solid catalysts. Oléagineux Corps Gras Lipides 1998, 5, 407-412.

24. Charles, G.; Clacens, J.-M.; Pouilloux, Y.; Barrault, J. Preparation de diglycerol et triglycerol par polymerisation directe du glycerol en presence de catalyseurs solides. Oléagineux Corps Gras Lipides 2003, 10, 74-82. [CrossRef]

25. Richter, M.; Krisnandi, Y.K.; Eckelt, R.; Martin, A. Homogeneous catalyzed batch reactor glycerol etherification by $\mathrm{CsHCO}_{3}$. Catal. Commun. 2008, 9, 2112-2116. [CrossRef] 
26. De Meulenaer, B.; Vanhoutte, B.; Huyghebaert, A. Development of chromatographic method fort he determination of degree of polymerisation of polyglycerols and polyglycerol fatty acid esters. Chromatographia 2000, 51, 44-52. [CrossRef]

27. Cassel, S.; Debaig, C.; Benvegnu, T.; Chaimbault, P.; Lafosse, M.; Plusquellec, D.; Rollin, P. Original synthesis of linear, branched and cyclic oligoglycerol standards. Eur. J. Org. Chem. 2001, 2001, 875-896. [CrossRef]

28. Iaych, K.; Dumarçay, S.; Fredon, E.; Gérardin, C.; Lemor, A.; Gérardin, P. Microwave-assisted synthesis of polyglycerol from glycerol carbonate. J. Appl. Polym. Sci. 2011, 120, 2354-2360. [CrossRef]

(c) 2017 by the authors. Licensee MDPI, Basel, Switzerland. This article is an open access article distributed under the terms and conditions of the Creative Commons Attribution (CC BY) license (http:/ / creativecommons.org/licenses/by/4.0/). 